\title{
In eigener Sache
}

\section{Sabine Kropp}

Mit dem nahenden Ende des 51. Jahrgangs der PVS ist über einige Veränderungen in den redaktionellen Abläufen und der personellen Zusammensetzung zu berichten. Im Oktober 2010 werden Rüdiger Schmitt-Beck und ich aus der Redaktion ausscheiden. Die Betreuung des Teilbereichs Methoden/Politische Soziologie wird von Rüdiger Schmitt-Beck (Uni Mannheim) auf Harald Schoen (Uni Bamberg) übergehen. Die Geschäftsführung der Redaktion übernimmt mit Heft 4/2010 mein Kollege Rainer Schmalz-Bruns (Uni Hannover), bei dem ich mich an dieser Stelle sehr herzlich für den guten und reibungslosen Übergang der Redaktionsgeschäfte von Speyer nach Hannover bedanken möchte. Neue Manuskripte sollten somit ab sofort in Hannover eingereicht werden.

In den vergangenen Jahren habe ich eine sehr kollegiale und vertrauensvolle Zusammenarbeit in der Redaktion erfahren, ganz gleich in welcher personellen Zusammensetzung. Mein Dank gilt neben den Kolleginnen und Kollegen auch Marie-Sophie Heinelt, unserer Redaktionsassistentin, für ihre sorgfältige, vorausschauende und zuverlässige Arbeit. Ebenso möchte ich mich beim VS Verlag für Sozialwissenschaften, namentlich Dr. Reinald Klockenbusch, für die gute Zusammenarbeit bedanken. Vorstand und Beirat der Deutschen Vereinigung für Politische Wissenschaft (DVPW) haben der Redaktion bei strategischen Fragen und den Weichenstellungen der vergangenen Jahre stets mit Rat und Tat zur Seite gestanden. Auch dies möchte ich eigens hervorheben; für die Unterstützung danke ich, stellvertretend für alle Beteiligten, Suzanne S. Schüttemeyer, Hubertus Buchstein und Felix Wurm sehr herzlich.

Das neue Redaktionsteam konnte die Zusammenarbeit im vergangenen halben Jahr bereits erproben. Nach meinem Eindruck hat sich der Übergang nahtlos und sehr gut vollzogen. Ich wünsche der neuen Redaktion und der Geschäftsführung unter Rainer Schmalz-Bruns viel Erfolg und bin sicher, dass die PVS von Hannover aus mit Engagement und Kompetenz geleitet werden wird.

\footnotetext{
Online publiziert: 02.09 .2010

(C) VS Verlag für Sozialwissenschaften 2010

Prof. Dr. S. Kropp $(\bowtie)$

Lehrstuhl für Politikwissenschaft,

Deutsche Hochschule für Verwaltungswissenschaften Speyer,

Freiherr-vom-Stein-Straße 2, 67346 Speyer, Deutschland

E-Mail:pvs@dhv-speyer.de
} 